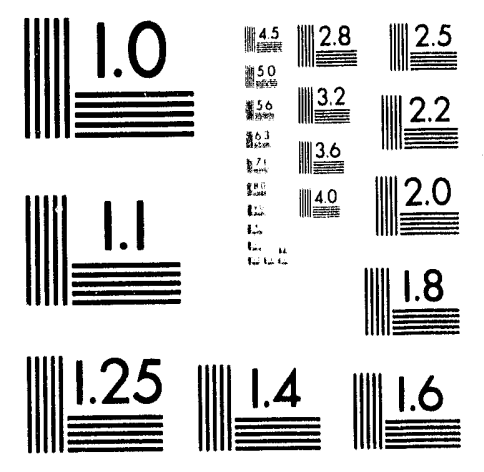



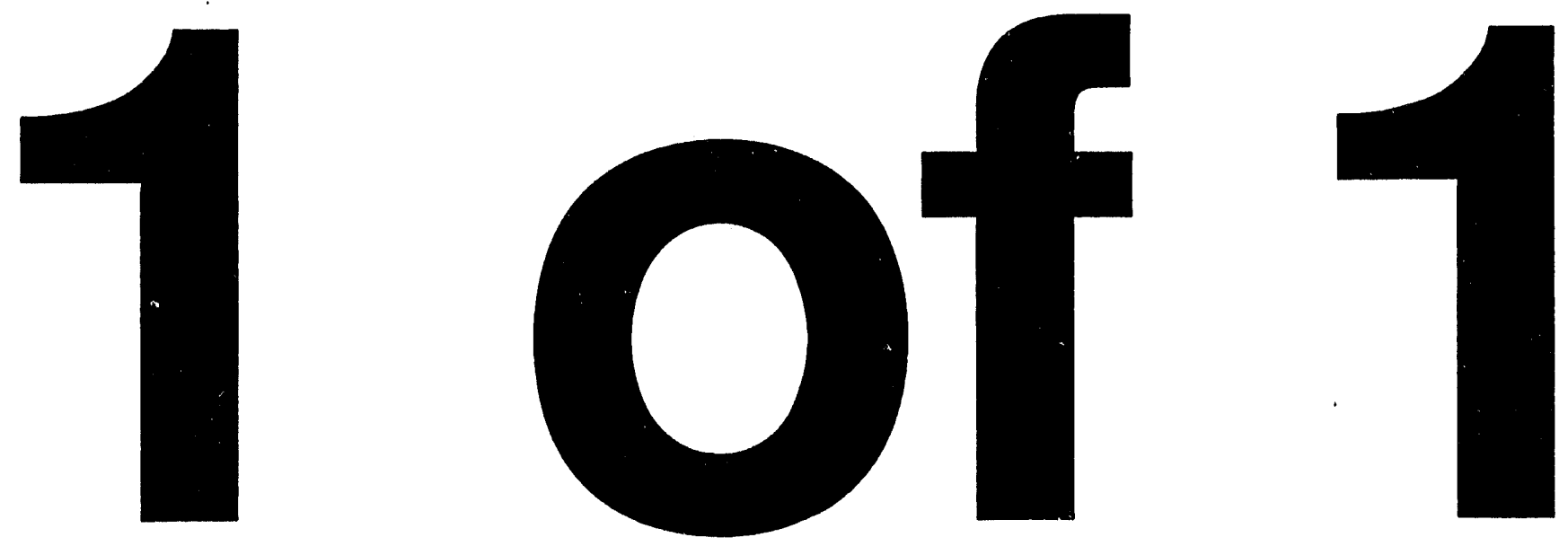


\section{ANL/DES/RP - 8C85}

The submitted manuscripl has been authored by a contractor of the U.S. Government uncler contract No. W-31-109-ENG-38. Accordingly, the U.S. Government retains nonexclusive, royalty-free license to publish or reproduce the published form of this contribution, or allow others to do so, for U.S. Government purposes.

\section{Diffusion of Irreversible Energy Technologies under Uncertainty}

James D. Cavallo and Ronald J. Sutherland

Economics and Law Section Decision and Information Sciences Division Argonne National Laboratory 9700 South Cass Avenue

Argonne, Illinois $60439-4832$

September, 1993

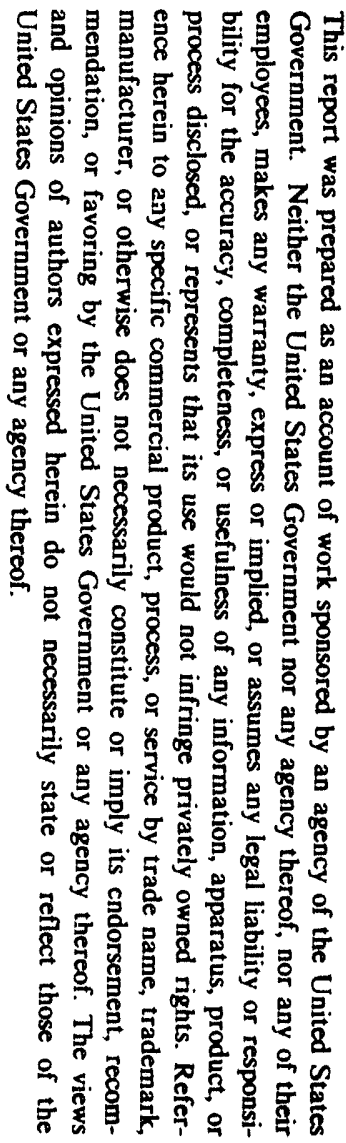

Work supported by the U.S. Department of Energy, Assistant Secretary for Policy, Planning, and Program Evaluation, Office of Economic Analysis, under contract W-31-109-ENG-38. 


\title{
Diffusion of Irreversible Energy Technologies under Uncertainty
}

\begin{abstract}
This paper presents a model of technology diffusion that is consistent with characteristics of participants in most energy markets. Whereas the models used most widely for empirical research are based on the assumption that the extended delays in adoption of cost-saving innovations are the result of either lack of knowledge about the new processes or heterogeneity across potential adopters, the model presented in this paper is based on the strategic behavior by firms. The strategic interdependence of the firms' decisions is rooted in spillover effects associated with an inability to exclude others from the learning-by-doing acquired when a firm implements a new technology. The model makes extensive use of recent developments in investment theory as it relates to irreversible investments under uncertainty.
\end{abstract}

\section{Introduction}

The U.S. Department of Energy (DOE) has an annual non-defense budget of about $\$ 6.8$ billion, most of which is used for research and development (O'Leary: 1993). In recent years, a sizeable amount of this funding has been shifted from longer term, basic research projects toward increased assistance in the implementation of currently available innovations in the marketplace. This change has stimulated concerns regarding the likelihood of diffusion into the marketplace of DOE sponsored technologies and the speed of that diffusion. The main purpose of this paper is to present considerations which will likely have major impacts on the rates of diffusion of the technologies developed by DOE.

Government support for basic research is generally not controversial. The benefits of basic research frequently are available as a public good through formal and informal communication of researchers, and these benefits often cannot be captured as property rights of the firm doing the initial research and develoment (R\&D). At the diffusion stage of a new technology, the government support finds less agreement. One view often expressed by industry representatives - for instance, the gas industry - is that DOE spends billions of dollars on R\&D but neglects to support the commercialization of technologies. The consequence of such neglect is that the potential consumer and producer surplus of these technologies are unrealized. A contrasting view that criticizes government support of technologies argues that such support is either not cost effective because the government cannot "pick winners" or that government support for technologies will create both free rider and crowding-out effects. Within the structure of the new game theoretic models, however, the arguments related to commercialization and diffusion can be viewed with the same economic concepts and the same basic framework as the basic research. 
Page 2

In recent years the theory associated with technology diffusion modeling has developed in an important direction to more fully and systematically incorporate the spillover effects of learning by doing. This progress has enabled modelers to represent the standard S-shaped diffusion path of an innovation as a consequence of economic optimization by interdependent decision makers (cf. Reinganum: 1981, Jovanovic and Lach: 1989, or Milgrom and Roberts: 1990), rather than random acquisition of knowledge about an innovation (cf. Mansfield: 1968 or Davis: 1979). The earlier models', such as the contagion and other probability-based diffusion models, remain important for some markets - especially in modeling the diffusion of technologies in industries that are widely dispersed geographically and have high costs to a the acquisition of information. However, the basic assumption of the contagion model - that the extended delay in the adoption of cost-saving innovations results from a lack of knowledge about new processes would seem inappropriate in many markets. For instance, in energy markets firms and individuals frequently exchange information about methods and technologies. ${ }^{2}$ The advantages of using the newer models, such as the game theoretic approach, to depict technology diffusion, however, extend beyond descriptive accuracy; the approach also suggests important policy recommendations for government agencies that support R\&D and the adoption of governmentsponsored technologies.

In this paper it is argued that the standard characteristics of the diffusion process - the $S$-shaped diffusion path - arise from several attributes common to new technologies ${ }^{3}$. Those attributes are: 1) uncertainty; 2) irreversibility; and 3) non-excludibility. Below we will model these three attributes. It will be shown that the combination of uncertainty and irreversibility leads to a lengthened diffusion process for any innovative technology by raising the hurdle for

${ }^{1}$ It should be noted that in many articles written on the topic of diffusion the major research interest has been testing two propositions that are associated with the writing of Joseph Schumpeter (1950, pp. 87-106). The two propositions are: 1) that technological change will occur with greater likelihood in concentrated markets; and 2) that technological change is more likely to occur in firms of larger size (cf. Kamien and Schwartz: 1982, p. 47). Though the testing of these hypotheses is very important to industrial organization, it holds less relevance to the issues currently before DOE. In part the different focus of purpose explains why much of the economic research on technology diffusion has not perfected models useful in estimating the speed of diffusion in energy markets.

${ }^{2}$ The gas and electricity industries have major research institutions - the Gas Research Institute and the Electric Power Research Institute - that develop and convey technical information to member firms.

3 One must note that DOE has a separate concern in externalities associated with energy technologies. Many of the environmentally bengin and energy-efficient innovations developed at national laboratories or universities with DOE support suffer a cost disadvantage when compared to technologies currently in use as a result of the failure to internalize the costs of pollution or the costs of dependence on foreign suppliers. This cost disadvantage may be expected to severely limit the diffusion of such DOE technologies unless there is a leveling of the playing field for competing technologies. For a discussion of externalities and technology diffusion, see Cavallo and Sutherland (1993). 
Page 3

the net return an innovative technology must meet above the level of the net return of the currently used process. That is, one cannot expect an innovation with a slightly higher expected return to be immediately adopted by industry if there are substantial sunk costs associated with the adoption of the innovation. By adding to our model the non-excludibility of learning gained through experience with an innovative process, it will be seen that there is the possibility of strategic waiting. By waiting for other firms to adopt the innovative technology, a firm can benefit from lower costs associated with the experience the other firms generate with the innovation.

This paper represents uncertainty in a different way than is usual in the irreversibilityuncertainty literature. Instead of including uncertainty as the stochastic return associated with a deterministic cost, our model represents uncertainty as a stochastic sunk costs that is recovered in a fixed net revenue stream throughout the life of the capital equipment. This assumption would seem more appropriate for regulated energy markets in which the portions of capital judged to be used and useful are entered into base utility rates. For instance, an investing utility often will not know until the capital is ready to be brought into service whether the entire investment will enter base rates, though afterwards the return on all the investment judged used and useful will be quite stable. It would also seem appropriate to associate the majority of randomness in energy investments with the sunk cost since the long lead time that are characteristic of energy investments severely reduces the ability of planners to accurately predict construction costs. By assuming stochastic sunk costs and stable net returns after operations begin, our formulation permits the use of an optimal stopping model to develop several results. These results conform to the usual findings of irreversibilty-uncertainty models.

Except for a greater likelihood of operating externalities and large stochastic sunk costs, the diffusion process of energy technologies are not different from the diffusion of any other innovation. The characteristics of fundamental changes in process technologies that we include in our model display the major features typical of the diffusion process. Repeatedly, researchers have found that new technologies diffuse slowly and that there is wide variation in the rates of diffusion for different technologies. It has also been repeatedly found that the diffusion process shows a mass movement to an innovation after a period of slow adoption - the steep portion of the sigmoid or $S$ curve. These features will be seen in our model. A further attractive feature of our model is that it represents the "energy conservation paradox" where energy technologies with a high potential for economic payoffs often show low adoption rates. In our model, we see why the uncertainty and irreversibility associated investments such as placing scrubbers on coalfired utility plants or building new nuclear generating plants may force a high hurdle rate on those technologies. Similarly, the reversibility of investments in such technologies and techniques as demand-side management (DSM) program may explain the remarkably fast adoption of DSM.

Though irreversibility and uncertainty are necessary components of technology diffusion models that do not rely on heterogeniety of firms or differences in the knowledge of participants in the market, a further element in the models are required. This is the incentive to wait for others to innovate in order that a firm can benefit frorn cost-saving knowledge gained by others having already innovated. The strategic waiting can substantially delay the benefits associated 
Page 4

with the introduction of a new technology if each firm in a market choses to wait for another to adopt first. Competitive markets may be more susceptible to the problem (cf. Jovanovic and Lach: 1989) than concentrated markets since firms with larger portions of the market are better able to capture more of the benefits of the cost savings associated with learning by doing and since a competitive firm that undertakes an irreversible investment before others could find itself using the innovation in a less profitable way than its competitors.

It can be argued that the Department of Energy and government in general can speed the diffusion process for innovative technologies characterized by uncertainty, irreversibility, and non-excludibility by undertaking the learning by doing as the production of a public good. Innovative processes would be expected to be adopted more quickly if uncertainty is reduced or if experience is developed by a public entity, e.g., universities or national laboratories. Though irreversibility would seem to be an unalterable part of the innovation, demonstration projects could be used to reduce the uncertainty surrounding new processes and develop publicly available experience. Whether the benefits of government actions to reduce uncertainty and increase experience are greater than the costs of those actions are, however, not obvious. It is certainly possible for the costs of producing the cost-saving knowledge though learning by doing to be much greater than the associated benefit. We will not attempt to examine the benefits and costs of government support for the diffusion process here. The reader will find an interesting discussion in Fishelson (1979).

In the second section of this paper, the uncertainty and irreversibility will be modelled using the theory of optimal stopping. In the third section, the strategic interdependence of one firm learning from another firm's experience is shown to prolong the diffusion process. Conclusions regarding government actions to reduce uncertainty will be reserved to the final section.

\section{Irreversibility as an Optimal Stopping Model}

In this section, a model will be developed in which a technological innovation will be assumed to be irreversible and incorporate an uncertain return to the adopter. As a frame of reference, one can think of a technology requiring a substantial but stochastic sunk cost, e.g., adopting the new nuclear technologies, adding a scrubber to a coal-fired electricity generating plant, or installing a residential gas absorption air conditioner. The model derives from the structure of optimal stopping models (cf. DeGroot: 1970, Chapter 13 and Eckstein and Wolpin: 1989). For the purposes of the model in this section, we will assume that the firm is a sufficiently small part of its market that it takes its market environment as fixed and uninfluenced by its actions. In particular, the firm will make its choices with the belief that the distributions of returns from a technological process will be independent of the firm's actions and unchanging through time.

It is assumed that a firm will attempt to maximize the expected value of its discounted future net revenues. If the firm chooses to innovate, it will be locked into the new technology for $\mathrm{T}+1$ periods. If it chooses not to innovate, the firm will be presented with the same choice 
Page 5

in the next period. The net revenues to the firm from the initial technological process will be $\pi_{1}\left(x_{v}\right)$ in period $t \in(1,2,3, \ldots)$. The state variable, $x_{t}$, determines the level of the net returns and is determined by past choices of the firm. Net revenues from the innovative process will be $\pi_{2}\left(x_{1}\right)$ in period $t$. We will assume that $\pi_{2}\left(x_{1}\right)$ is stochastic until the innovative process is adopted. ${ }^{4}$ That is to say, if adoption occurs in period $t, \pi_{2}\left(x_{\mathbf{s}}\right)=\pi_{2}\left(x_{2}\right)$ for all $s \in\{t, T+t\}$. All future returns are discounted by the factor $\beta$, with $0<\beta<1$. The firm's maximization problem is:

$$
v_{1}\left(x_{1}\right)=\max _{u_{1} \in\{0,1\}} E\left\{\sum^{T}{ }_{t=1} \beta^{1-1}\left[\pi_{1}\left(x_{t}\right)\left[1-u_{t}\right]+\pi_{2}\left(x_{1}\right) u_{t}\right]\right\}
$$

The control variable in this dynamic program is $u_{4} \in\{0,1\}$. Since the adoption of the innovative process is irreversible, $u_{1}=1$ implies the innovative process is used for all periods $s \in\{t, T+t\}$. To represent this irreversibility, the state variable, $x_{1}$, is determined with the following transition function

$$
x_{t+1}= \begin{cases}x_{t}+u_{1} & \text { if } x_{t}=0 \\ x_{t} & \text { if } x_{t}=1\end{cases}
$$

for $t \in\{1, \mathrm{~T}-1\}$ and with the initial condition $\mathrm{x}_{0}=0$. By constructing the state variable as in Eq. 2, we represent the information available to the firm at time t, i.e., the adoption decision in any previous period. As is usual in models of this type, it will also be assumed that the firm knows the essential characteristics of the stochastic process. The stochastic process will be represented as a time-independent distribution function, $F(y)$, of the random variable, $\pi_{2}(0)$. A realization of the random variable in time $t$ will be denoted by $y_{t}$.

The maximization problem of the firm can be rewritten as a recursive functional and is given in Eq. 3:

$$
v_{1}\left(x_{1}\right)=\max _{u_{t} \in\{0,1\}}\left\{\left[\pi_{1}\left(x_{1}\right)+\beta \int v_{t+1}\left(x_{t+1}\right) d F\right]\left[1-u_{1}\right]+\left[\pi_{2}\left(x_{1}\right)+\beta v_{t+1}(1)\right] u_{t}\right\}
$$

Eq. 3 is derived by working backward from $v_{T}\left(x_{T}\right)$, which is a simple choice between $\pi_{1}\left(x_{T}\right)$ and the realization of the random variable $\pi_{2}\left(\mathrm{x}_{\mathrm{T}}\right)$. For period T-1, the function $\mathrm{v}_{\mathrm{T}-1}\left(\mathrm{x}_{\mathrm{T}-1}\right)$ is the more complicated choice between $\pi_{1}\left(x_{T-1}\right)$ plus the discounted expected value of $v_{T}\left(x_{T}\right)$ given $u_{T-1}=0$ and $\pi_{2}\left(x_{T-1}\right)$ plus the discounted expected value of $v_{T}\left(x_{T}\right)$ given $u_{T-1}=1$. Recursively one can work backward to find $v_{1}\left(x_{1}\right)$ for any period $t \in\{0,1, \ldots, T\}$.

${ }^{4}$ One may think of the stochastic nature of $\pi_{2}\left(x_{1}\right)$ as arising from a sunk cost associated with innovative process. The sunk cost could be fluctuating through time and observed each period. When the adoption choice is made, the annualized expense of the sunk cost are incorporated into the net revenues of the firm. 
There are three possible net returns to the firm. These are given in the matrix below:

$$
\begin{array}{lcc} 
& \pi_{1}\left(\mathrm{x}_{1}\right) & \pi_{2}\left(\mathrm{x}_{1}\right) \\
\mathbf{x}_{\mathrm{t}}=0 & \pi_{1}(0) & \pi_{2}(0) \\
\mathrm{x}_{\mathrm{t}}=1 & - & \pi_{2}(1)
\end{array}
$$

The element $\pi_{2}(0)$ is a fresh draw from a probability distribution, $F\left(y_{1}\right), \pi_{2}(1)$ is the return from an earlier draw, $y_{1}$, where $s$ is the period when the innovative process was adopted. There is no element for $\pi_{1}(1)$ due to irreversibility. Given these returns, Eq. 3 can be simplified to show the dichotomous nature of the choice in period $t$.

$$
\begin{aligned}
& v_{t}(0)=\max \left\{\pi_{1}(0)+\beta \int v_{t+1}(0) d F, y_{t} \sum^{T}{ }_{t-t} \beta^{t-1}\right\} \\
& \left.v_{t}(1)=y_{t} \sum^{T}{ }_{t-1} \beta^{a-1}\right\} \quad \text { where } \tau \text { is the period when the innovative process was adopted }
\end{aligned}
$$

Since Eq. $4 \mathrm{~b}$ does not present a decision problem, it can be ignored.

If it is assumed that $\pi_{1}\left(x_{J}\right)$ is constant for all $t$, the standard optimal stopping result is a reservation return that is monotonically increasing in $\mathrm{T}$. Let $\pi_{\mathrm{T}}{ }^{*}$ be defined as the reservation price where the investment is irreversible for $T$ years. A reservation return greater than the return from the currently used process may be interpreted as a hurdle which the innovative process must surmount in order to find adoption. That is, if $\pi_{1}(0)=r>0$, then $\pi_{\mathrm{T}}{ }^{*}>\mathrm{r}$ implies the new process will be adopted only if its return exceeds the return of the older process by $\pi_{\mathrm{T}}{ }^{*}-\mathrm{r}$ or more. A return from the new process equal to that of the old, or greater by an amount less than $\pi_{\mathrm{T}}{ }^{*}-\mathrm{r}$, will not result in adoption.

To see this important result, let us first consider the model if the innovative process is not irreversible. A reversible process is equivalent to the assumption in Eq. 1 of $\mathrm{T}=1$, or that the firm can choose again between the old and the innovative processes after the current period. Since the next period's choice is not restricted by the choice in the current period, the firm will choose the process with the higher current period return. That is, the choice will be the larger of $r$ and the realization of the random process, $y_{1}$. Therefore the reservation return is given as $\pi_{1}^{*}=r$. So long as $y_{1} \geq r$, the innovative process will be adopted.

Now let us consider the problem of Eq. 1 if $T=2$. In this case, the decision to innovate in the current period restricts the next period by no later period. For $T=2$, the problem is given by

$$
v_{1}(0)=\max \left\{r+r \beta \int_{0}^{r} d F+\beta \int_{r}^{\infty} y_{2} d F, y_{1}(1+\beta)\right\}
$$

The value of this function is the maximum of receiving a current period return of $r$ plus the discounted expected value of making another choice in period 2 or stopping with the realization $y_{1}$ and being restricted from taking advantage of a possibly higher realization $y_{2}$. The expected 
value of another choice in period 2 has two components depending on whether or not the realization $y_{2}$ is below the reservation return. The probability that $y_{2}$ is less than $r$ is $\int_{0}{ }_{0} d F$. If $y_{2}$ is less than $r$, the firm will surely choose the return $r$, and this component of the expected value is $r \int_{0}^{r} d F$. The other component of the expected value is $y_{2}$ multiplied by the probability of $y_{2}$ occuring for all $y_{2} \geq r$. This problem can be rewritten as

$$
v_{1}(0)=\max \left\{r(1+\beta)+\beta \int_{r}^{\infty}\left(y_{2}-r\right) d F, y_{1}(1+\beta)\right\}
$$

Thus the choice will be to adopt in period $\hat{i}$ if

$$
\mathrm{r}(1+\beta)+\beta \int_{\mathrm{r}}^{\infty}\left(\mathrm{y}_{2}-\mathrm{r}\right) \mathrm{dF} \leq \mathrm{y}_{1}(1+\beta)
$$

or

$$
[\beta /(1+\beta)] \int_{r}^{\infty}\left(y_{2}-r\right) d F \leq y_{1}-r
$$

Since the left-hand side of the inequality must be greater than zero, the reservation return for $T=2$ (i.e., the value for $y_{1}$ that results in equality) must be greater than or equal to $r$. That is,

$$
\pi_{2}^{*}=r+[\beta /(1+\beta)] \int_{r}^{\infty}\left(y_{2}-r\right) d F>0
$$

or

$$
\pi_{2}^{*}-\mathrm{r}=[\beta /(1+\beta)] \int_{\mathrm{r}}^{\infty}\left(\mathrm{y}_{1}-\mathrm{r}\right) \mathrm{dF} \geq 0
$$

It is useful to simplify the notation by defining a function $G(x)$ :

$$
G(x) \equiv \int_{x}^{\infty}\left(y_{t}-x\right) d F
$$

Two easily verified properties of $G(x)$ are: $G(x) \geq 0$ and $d G(x) / d x=F(x)-1 \leq 0$. With this altered notation, Eq. 5 becomes

$$
\pi_{2}^{*}-\mathrm{r}=[\beta /(1+\beta)] \mathrm{G}(\mathrm{r}) \geq 0
$$

In general, the assumption of $\pi_{1}(0)=r>0$ specializes Eq. $4 a$ to

$$
v_{1}(0)=\max \left\{r+\beta \int v_{t+1}(0) d F, y_{1} \sum^{T}+\ldots+1 \beta^{n-1}\right\}
$$

This function equals the maximum of receiving a current period return of $r$ plus the discounted expected value of having a choice in the next period or stopping with the realization $y_{t}$ and being restricted from taking advantage of a possibly higher realization in ..ume period between $t$ and $\mathrm{T}$. Working recursively back from $\mathrm{v}_{\mathrm{T}}(0)$ and $\pi_{1}{ }^{*}$, one transforms this function to 
Page 8

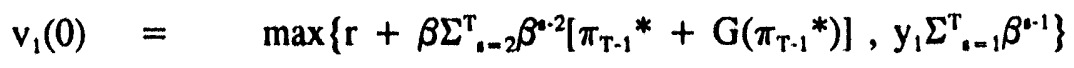

The reservation return $\pi_{\mathrm{T}}{ }^{*}$ is found to be

$$
\pi_{\mathrm{T}}^{*}=\left\{\mathrm{r}+\beta \Sigma^{\mathrm{T}}{ }_{\mathrm{i}-2} \beta^{r-2}\left[\pi_{\mathrm{T}-1}{ }^{*}+\mathrm{G}\left(\pi_{\mathrm{T}-1}{ }^{*}\right)\right]\right\} / \Sigma^{\mathrm{T}}{ }_{,-1} \beta^{r-1}>0
$$

It will be shown that Eq. 7 implies $\pi_{\mathrm{T}}{ }^{*} \geq \pi_{\mathrm{T}-1}{ }^{*}$. First note that $\pi_{\mathrm{r}}{ }^{*}-\pi_{\mathrm{T}-1}{ }^{*} \leq \mathrm{G}\left(\pi_{\mathrm{T}-1}{ }^{*}\right)$ because

$$
\begin{array}{ll}
\Sigma^{\mathrm{T}}{ }_{t-1} \beta^{*-1} \pi_{\mathrm{T}}{ }^{*}= & \mathrm{r}+\beta \Sigma^{\mathrm{T}}{ }_{t-2} \beta^{*-2}\left[\pi_{\mathrm{T}-1}{ }^{*}+\mathrm{G}\left(\pi_{\mathrm{T}-1}{ }^{*}\right)\right] \\
\pi_{\mathrm{T}}{ }^{*}+\beta \Sigma^{\mathrm{T}}{ }_{t-2} \beta^{\mu-2} \pi_{\mathrm{T}}{ }^{*}= & \mathrm{r}+\beta \Sigma^{\mathrm{T}}{ }_{t-2} \beta^{*-2}\left[\pi_{\mathrm{T}-1}{ }^{*}+\mathrm{G}\left(\pi_{\mathrm{T}-1}{ }^{*}\right)\right]
\end{array}
$$

and, since it is clear from Eq. 7 that $\pi_{\mathrm{T}}{ }^{*} \geq \mathrm{r}$,

$$
\begin{gathered}
\beta \Sigma^{\mathrm{T}}{ }_{\mathrm{s}-2} \beta^{\theta-2} \pi_{\mathrm{T}}{ }^{*} \leq \beta \Sigma^{\mathrm{T}}{ }_{\mathrm{s}-2-2} \beta^{*-2}\left[\pi_{\mathrm{T}-1}{ }^{*}+\mathrm{G}\left(\pi_{\mathrm{T}-1}{ }^{*}\right)\right] \\
\pi_{\mathrm{T}}{ }^{*}-\pi_{\mathrm{T}-1}{ }^{*} \leq \mathrm{G}\left(\pi_{\mathrm{T}-1}{ }^{*}\right)
\end{gathered}
$$

Now using Eq. 7 to subtract $\pi_{\mathrm{T}-1}{ }^{*}$ from $\pi_{\mathrm{T}}{ }^{*}$, we have

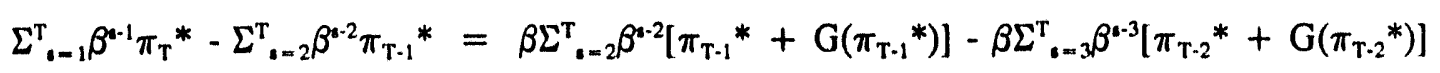

Subtracting $\beta^{\mathrm{T}-1} \pi_{\mathrm{t}-1} *$ from both sides,

$$
\Sigma^{\mathrm{T}=-1} \beta^{r-1}\left[\pi_{\mathrm{T}}{ }^{*}-\pi_{\mathrm{T}-1}{ }^{*}\right]=\beta \Sigma^{\mathrm{T}}{ }_{\mathrm{r}-2} \beta^{s-2} \mathrm{G}\left(\pi_{\mathrm{T}-1}{ }^{*}\right)+\beta \Sigma^{\mathrm{T}}{ }_{\mathrm{i}-3} \beta^{*-3}\left[\pi_{\mathrm{T}-1}{ }^{*}-\pi_{\mathrm{T}-2}{ }^{*}-\mathrm{G}\left(\pi_{\mathrm{T}-2}{ }^{*}\right)\right]
$$

but since $\pi_{\mathrm{T}-1}{ }^{*}-\pi_{\mathrm{T}-2}{ }^{*} \leq \mathrm{G}\left(\pi_{\mathrm{T}-2}{ }^{*}\right)$

$$
\Sigma^{\mathrm{T}}{ }_{\mathrm{s}-1} \beta^{*-1}\left[\pi_{\mathrm{T}}{ }^{*}-\pi_{\mathrm{T}-1}^{*}\right] \geq \beta \Sigma^{\mathrm{T}}{ }_{\mathrm{k}=2} \beta^{* \cdot 2} \mathrm{G}\left(\pi_{\mathrm{T}-1}^{*}\right) \geq 0
$$

which proves that $\pi_{\mathrm{T}}{ }^{*} \geq \pi_{\mathrm{T}-1}{ }^{*}$ and that the reservation return increases monotonically in $\mathrm{T}$ for such fixed horizon technology diffusion problems.

The intuition of this result can be seen by considering Eq. 1 without the irreversibility restriction. If a firm could cheaply switch between the two technological processes in each period, then the firm would choose the process with the highest net return each period. The reservation return for the innovative process would be equal to the return from the older technology, and each period would then be like Eq. 1 with $\mathrm{T}=1$. It is only the combination of irreversibility and uncertainty that raises the reservation return for $\mathrm{T}>1$ above the return to the older technology. As $\mathrm{T}$ increases - i.e., as the period of irreversibility of the technology lengthens - the firm's opportunities to take advantage of possibly higher realizations of returns to the innovation are further restricted. In an important sense, the choice of the innovative process closes of the option of choosing a higher return for the next $\mathrm{T}$ periods, and as $\mathrm{T}$ increases 
Page 9

more options are closed with the choice of the innovative technology.

The finding that the nexus of irreversibility and uncertainty implies that an innovative process will require a return higher than the return from a known, currently-used process (except in the terminal period) is also developed by Hassett and Metcalf: forthcoming). Our model, however; associates uncertainty with the sunk costs of the investment and holds the return from the innovation constant after its introdisction.

\section{Strategic Interdependence through Non-excludible Learning by Doing}

The model developed in section 2 can be extended to include interdependence between firms which can lead to firms strategically waiting for others to adopt an innovations. Strategic waiting can arise if the experience generated by adopting a new technology can not be contained within the firm, but is a collectively consumed good. By implementing an innovation, firms often discover cost saving variations on the process (cf. Davies: 1979, p. 49). Such learning by doing frequently can not be excluded from others. Through professional interaction between scientists and managers within an industry, hiring experienced personnel, and direct observation of output one firm can learn from another at little cost. In the energy markets, spillover between firms from learning by doing is particularly easy since government and industrial institutes devote many resources to iceping firms informed about technological innovations.

Models that include spillovers of learning by doing between firms have been examined by Arrow (1962), Reinganum (1981), Jovanovic and I ach (1989), and Milgrom and Roberts (1990). Here we offer a model which builds on the theory developed in section 2.

In Eq. 8, the firm $i$ is one member of the industry. The firm will be assumed to learn from any other member of the industry if the process innovation is implemented. The firm's maximization problem is:

$$
v_{i 1}\left(x_{i 1}, x_{-i 1}\right)=\max _{u_{i 1} \in\{0,1\}} E\left\{\sum^{\mathrm{T}}{ }_{t=1} \beta^{t-1}\left[\pi_{i 1}\left(x_{i t}, x_{-i t}\right)\left[1-u_{i t}\right]+\pi_{i 2}\left(x_{i t}, x_{-i t}\right) u_{i t}\right]\right\}
$$

As before, the control variable, $u_{i 1}$, is dichotomous and displays irreversibiltiy by remaining at the value 1 for all periods $s \in\{t, T+t-1\}$ if the adoption of the innovative technology at time $t$. There are two state variables in Eq. 8. The first, $x_{i t}$, represents the current choice of firm $i$ and is given by a transition function identical to Eq. 2 .

\footnotetext{
${ }^{5} \mathrm{~A}$ similar result can be shown in an infinite horizon version of the model in Eqs. 1 and 2. In such a model, a stationary solution is found in which the reservation return for the innovative process is always above the return from the older technological process (DeGroot: 1970, pp. 324-349). An infinite horizon model, however, would suggest that the innovative process is irreversible for all future periods.
} 
Page 10

$$
x_{i t+1}= \begin{cases}x_{i t}+u_{i t} & \text { if } x_{i t}=0 \\ x_{i t} & \text { if } x_{i t}=1\end{cases}
$$

for $t \in\{1, T-1\}$ and with the initial condition $x_{i 0}=0$. The second state variable, $x_{-i t}$, represents the current choice of all other firms. The transition function for $x_{-i t}$ is given in $\mathrm{Eq}_{1} 10$.

$$
x_{\cdot i t+1}= \begin{cases}x_{\cdot i t}+u_{-i t} & \text { if } x_{-i t}=0 \\ x_{\cdot i t} & \text { if } x_{-\cdot i t}=1\end{cases}
$$

for $t \in\{1, T-1\}$ and with the initial condition $x_{-i 0}=0$.

As before, we shall represent the return from the innovative technology as stochastic until adoption and then fixed for $T$ periods. We now have the additional state variable for the choices of the other firms in the market. The various possible net returns are given below:

$\begin{array}{ccccc} & \pi_{\mathrm{i} 1}\left(\mathrm{x}_{\mathrm{ir}}, 0\right) & \pi_{\mathrm{i} 1}\left(\mathrm{x}_{\mathrm{ir}}, 1\right) & \pi_{\mathrm{i} 2}\left(\mathrm{x}_{\mathrm{ir}}, 0\right) & \pi_{\mathrm{i} 2}\left(\mathrm{x}_{\mathrm{ir}}, 1\right) \\ \mathrm{x}_{\mathrm{it}}=0 & \mathrm{r} & \mathrm{r} & \pi_{\mathrm{i} 2}(0,0) & \pi_{\mathrm{i} 2}(0,1) \\ \mathrm{x}_{\mathrm{it}}=1 & - & - & \mathrm{y}_{\mathbf{6}} & \mathrm{z}_{\mathrm{i}}\end{array}$

The net return $\pi_{i 2}(0,0)$ is a fresh draw from a probability distribution, as is $\pi_{i 2}(0,1)$. The expected probability distributions for the two draws are not the same, however; and the expected value of $\pi_{i_{2}}(0,0)$ is less than the expected value of $\pi_{\mathrm{i} 2}(0,1)$ due to non-excludible learning by doing. As in section 2, the return to the firm before adopting the innovative process is fixed at $r$, and the return to the firm in periods after it has adopted the process are fixed at the level $y_{\text {, }}$ or $z_{4}$ which are earlier draws from either the probability distribution of $\pi_{i 2}(0,0)$ or $\pi_{i 2}(0,1)$.

As with the model in section 2, this formulation can be transformed into a recursive problem which can be solved hackwards from the terminal period. We can consider first the decision problem of the firm after another firm has adopted the innovative process and generated the non-excludible experience. This decision problem is identical to that of section 2 and is given in Eq. 11 below:

$$
v_{i 1}(0,1)=\max \left\{r+\beta \int v_{i 2}(0,1) \mathrm{dF}_{1}, z_{1} \sum^{\mathrm{T}}{ }_{\mathrm{i}-1} \beta^{\mathrm{s}-1}\right\}
$$

In this decision problem, the random drawing $z_{1}$ is from the probability distribution for $\pi_{i 2}(0,1)$, $F_{1}\left(z_{1}\right)$. As before, the firm would choose to adopt the innovation only if the discounted stream of returns $z_{1}$ is greater than accepting another period's return $r$ plus the discounted expected value of the choice next period. The reservation return for this problem will be identical to that of $\mathrm{Eq}$. 7 with the function $G($.$) defined using F_{1}\left(z_{1}\right)$. 
Page 11

We can make this explicit by defining $G_{0}($.$) and G_{1}($.$) as follows:$

$$
\begin{aligned}
& G_{0}(x) \equiv \int_{x}^{\infty}\left(y_{1}-x\right) d F_{0} \\
& G_{1}(x) \equiv \int_{x}^{\infty}\left(z_{1}-x\right) d F_{1}
\end{aligned}
$$

The reservation return for Eq. 11 is then given by Eq. 12:

$$
\pi_{\mathrm{T}}{ }^{*}(1)=\left\{\mathrm{r}+\beta \Sigma^{\mathrm{T}}{ }_{1=2} \beta^{*-2}\left[\pi_{\mathrm{T}-1}{ }^{*}(1)+\mathrm{G}_{1}\left(\pi_{\mathrm{T}-1}{ }^{*}(1)\right)\right]\right\} / \Sigma^{\mathrm{T}}{ }_{\uparrow-1} \beta^{*-1}
$$

where $\pi_{T}^{*}(1)$ is the reservation return given $x_{-i 1}=1$

If no other firm has adopted the innovative process by period $t$, the firm's choice is somewhat more complex. Here the firm must estimate the likelihood of another firm adopting the innovation in the current period because such an adoption by another firm will have an effect on the discounted expected value of the choice next period. If we labci this subjective probability p, the decision problem can be represented as in Eq. 13:

$$
\mathrm{v}_{\mathrm{i} 1}(0,0)=\max \left\{\mathrm{r}+\beta\left[(1-\mathrm{p}) \int \mathrm{v}_{\mathrm{i} 2}(0,0) \mathrm{dF}_{0}+\mathrm{p} \int \mathrm{v}_{\mathrm{i} 2}(0,1) \mathrm{dF}_{1}\right], \mathrm{y}_{1} \Sigma^{\mathrm{T}} \mathrm{i-1} \beta^{n-1}\right\}
$$

There are two important points to make about Eq. 13. The first is that the expected value of the making a choice in the next period is a blend of two probability distributions $-F_{0}$, the probability distribution of $\pi_{i 2}(0,0)$, and $F_{1}$, the probability distribution of $\pi_{i 2}(0,1)$. Due to the spillover between firms from learning by doing, the expected return from the distribution $F_{0}$ is less than the expected return from $F_{1}$, - i.e., $\int y_{2} d F_{0}<\int z_{2} d F_{1}$. The second point is that $y_{1}$ is drawn from the probability distribution $F_{0}$. Therefore, if the firm believes there is a nonnegligible probability of another firm adopting the innovative technology in the next period - or, through recursion, in any future period - the random draw $y_{1}$ from the probability distribution with the lower expected value will be compared in part with the possibility of a draw next period from the probability distribution with the higher expected value.

This result can be derived from the reservation return implied by Eq. 13. Solving recursively from $\mathrm{T}$ back to $t=1$, we find $\mathrm{Eq}$. 14:

$$
\pi_{\mathrm{T}}^{*}(0)=\left\{\mathrm{r}+\beta \Sigma^{\mathrm{T}}{ }_{\mathrm{i}-2} \beta^{r \cdot 2}\left\{(1-\mathrm{p})\left[\pi_{\mathrm{T}-1}{ }^{*}(0)+\mathrm{G}_{1}\left(\pi_{\mathrm{T}-1}{ }^{*}(0)\right)\right]+\mathrm{p}\left[\pi_{\mathrm{T}-1}{ }^{*}(1)+\mathrm{G}_{1}\left(\pi_{\mathrm{T}-1}{ }^{*}(1)\right)\right]\right\}\right\} / \Sigma^{\mathrm{T}}{ }_{\mathrm{s}=1} \beta^{s-1}
$$

where $\pi_{T}^{*}(0)$ is the reservation return given $x_{\cdot i 1}=0$. Eq. 14 is composed to two parts due to the possibility of another firm choosing to adopt the innovative technology and lowering the costs for firm $\mathrm{i}$ of producing with the innovative process. By substituting Eq. 12 into Eq. 14, we find

$$
\pi_{\mathrm{T}}^{*}(0)=(1-\mathrm{p})\left\{\mathrm{r}+\beta \Sigma^{\mathrm{T}}{ }_{\mathrm{s}-2} \beta^{\mathrm{r}-2}\left\{(1-\mathrm{p})\left[\pi_{\mathrm{T}-1}{ }^{*}(0)+\mathrm{G}_{1}\left(\pi_{\mathrm{T}-1}{ }^{*}(0)\right)\right]\right\} / \Sigma^{\mathrm{T}}{ }_{--1} \beta^{-1}+\mathrm{p} \pi_{\mathrm{T}}^{*}(1)\right.
$$

From Eq. 15 we can compare the expected hurdle firm $i$ will face before and after other firms adopt the innovation. Assuming that the impact of spillover from the experience of another firm is to uniformly shift the distribution of possible returns for the innovative process, Eq. 15 
implies that $\pi_{\mathrm{T}}^{*}(1) \geq \pi_{\mathrm{T}}{ }^{*}(0)$. But by this assumption, the difference between $\pi_{\mathrm{T}}{ }^{*}(1)$ and $\pi_{\mathrm{T}}{ }^{*}(0)$ can not be greate: than the difference between the expected values $\int z_{2} \mathrm{dF}_{1}$ and $\int \mathrm{y}_{2} \mathrm{dF}_{0}$ because the expected values are summations over the entire distributions $F_{1}$ and $F_{0}$ respectively while the reservation returns differ only where they are partial summations over the same distributions. (Recall that the reservation returns are composed of two parts: the first part, $r$, is shared by both reservation returns; and the second part is a summation over the part of $F_{1}$ and $F_{0}$ above the reservation returns.) Therefore, the expected hurdle for the firm will decrease after other firms adopt the innovation. That is, $\int \mathrm{z}_{2} \mathrm{dF}_{1}-\pi_{\mathrm{T}}^{*}(1) \leq \int \mathrm{y}_{2} \mathrm{dF}_{0}-\pi_{\mathrm{T}}{ }^{*}(0)$. Depending on the subjective probability of the manager of firm $i$ and his/her time preference, it may be optimal to strategically wail for another firm to adopt the innovation.

The important conclusion here is that the inclusion of learning from another's experience can encourage firms to wait for others to adopt the innovation. In all cases it increases the hurdle a random draw from the probability distribution $F_{0}$ must surmount in order to be accepted and locked in. Obviously, the larger the expected cost saving from the other's experience, the greater the hurdle and the greater the likelihood of waiting. After the adoption by one firm, however, the difference between the expected draw and the reservation return is lower and one would expect more firms to adopt. This type of behavior is consistent with the behavior observed in real markets as typified by the sigmoid or $S$ curve.

\section{Conclusions}

This paper has presented a model of technology diffusion based on three assumed characteristics common among energy technologies. Those characteristics are: 1) uncertainty of initial sunk costs; 2) irreversibility of investment; and 3) non-excludibility of cost-saving knowledge gained in the process of implementing an innovative process. We have derived the standard results seen in industry - i.e., that few firms will adopt an innovation initially while after a period of slow diffusion many firms choose the innovation in quick succession. As important as the characteristics of the model that were assumed, it is equally important that we have not assumed either a lack of knowledge on the part of some firms - as in the contagion model - or a heterogeneity among firms. It would appear inconsistent with the characteristics of energy markets to assume a substantial delay in firms learning about new innovations or to assume that one firm is substantially different from another in the industry.

The essential result of this study of diffusion is that the process of technology adoption can cause a coordination problem as firms wait for others to adopt an innovation so that they can benefit from the spillover effects of learning by doing. However, as firms wait for others, some of the benefits to consumers and to the firms can be lost. Government can stimulate the process of diffusion through actions such as demonstration projects. Demonstration projects can be an effective and equitable way to support the diffusion of particular technologies. They can stimulate the spread of knowledge of an innovation and generate the learning by doing that firms may be waiting for. This can be cost-effective if the benefits of the innovation are great, the incentive to wait is sufficiently high, and the cost of the governmental action is low. The market avoids the coordination problem of determining which firm innovates first and the costs of the 


\section{Page 13}

learning are borne by the society at large and not by any individual firm. An additional advantage is that the learning is available to all market participants and would not be susceptible to attempts by firms to exlude competitors. 


\section{Bibliography}

Arrow, Kenneth J. (1962): "The Economic Implications of Learning by Doing", Review of Economic Studies, 29, June, pp. 155-174.

Cavallo, James D., and Ronald J. Sutherland (1993): "Policies for Energy Technology Diffusion", a paper presented at the Western Economics Association annual meetings, June.

Davies, Stephen (1979): The Diffusion of Process Innovations (Cambridge University Press).

DeGroot, Morris H. (1970): Optimal Statistical Decisions (McGraw-Hill Book Company).

Eckstein, Zvi, and Kenneth I. Wolpin (1989): "The Specification and Estimation of Dynamic Stochastic Discrete Choice Models", Journal of Human Resources, 24(4), Fall, pp. 562-598.

Fishelson, Gideon (1979): "Measuring the Benefits from an Innovation", Energy Economics, January, pp.47-52.

Hassett, Kevin A., and Gilbert E. Metcalf (1992): "Energy Conservation Investment: Do Consumers Discount the Future Correctly?", forthcoming.

Jovanovic, Boyan, and Saul Lach (1989): "Entry, Exit, and Diffusion with Learning by Doing", American Economic Review, 79(4), September, pp. 690-699.

Kamien, Morton I., and Nancy L. Schwartz (1982): Market Structure and Innovation (Cambridge University Press).

Mansfield, Edwin (1968): Industrial Research and Technological Innovation (W.W. Norton).

Milgrom, Paul, and John Roberts (1990): "Rationalizability, Learning, and Equilibrium in Games with Strategic Complementarities", Econometrica, 58(6), November, pp. 1255-1277.

O'Leary, Hazel R. (1993): "U.S. Department of Energy Budget Highlights", U.S. Department of Energy Report, April.

Reinganum, Jennifer (1981): "Market Structure and the Diffusion of New Technology", Bell Journal of Economics, 12(2), Autumn, pp. 618-624.

Reinganum, Jennifer (1989): "The Timing of Innovation: Research, Development, and Diffusion", in Richard Schmalensee and Robert Willig, ed.: Handbook of Industrial Organization, Vol. 1, (North-Holland), pp. 849-908.

Schumpeter, Joseph (1950): Capitalism, Socialism, and Demorracy (Hàrper \& Row). 

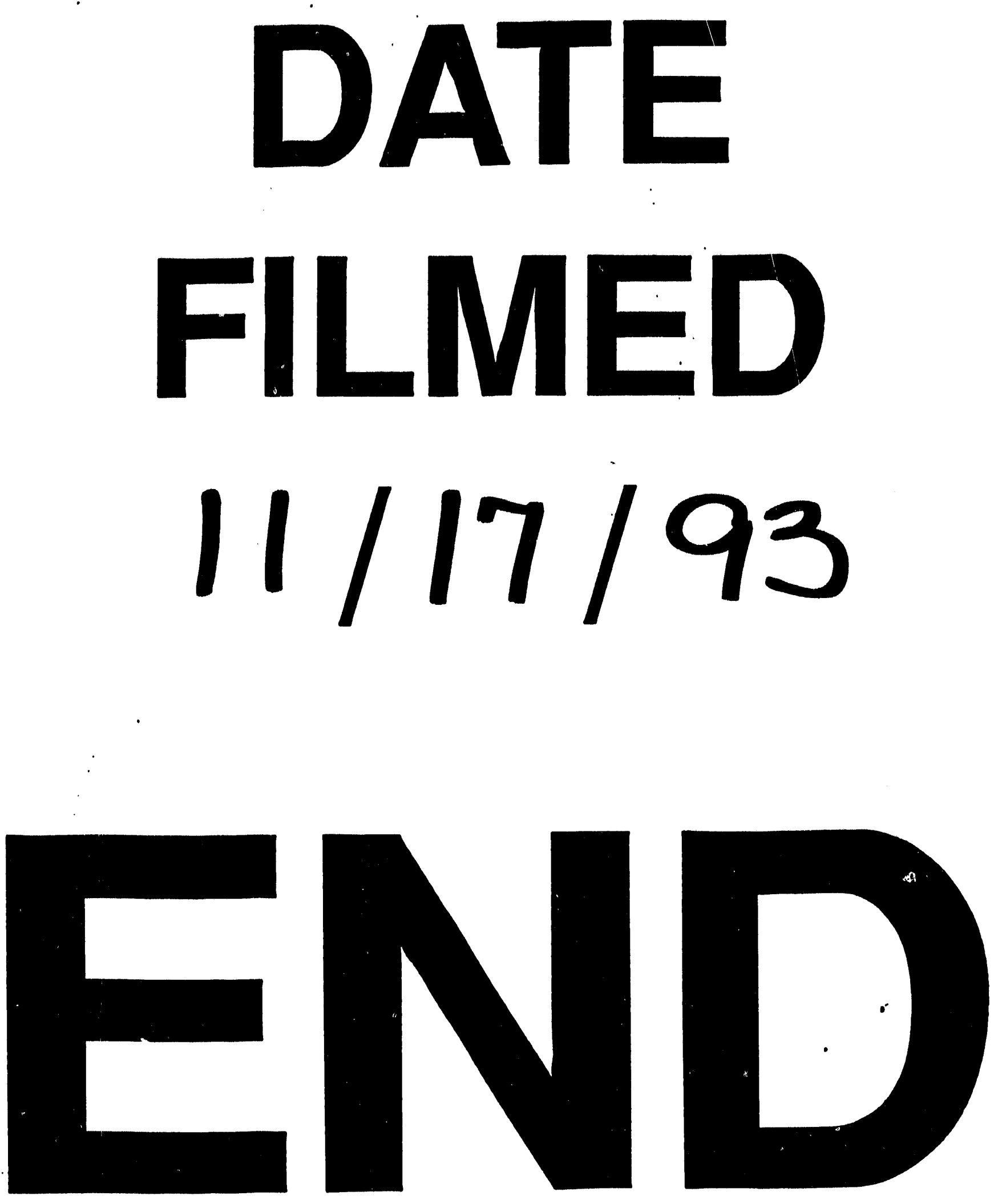


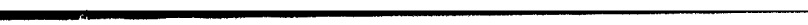

$$
\text { ( }
$$

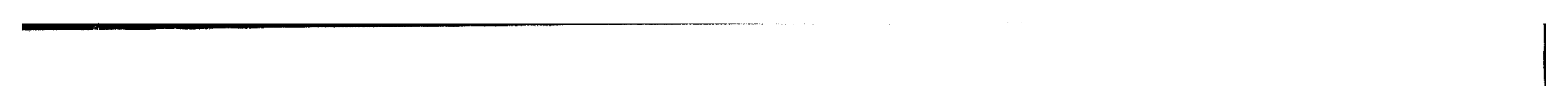

